\title{
Proceeding
}

Supplementary Issue: Rio 2016 Olympic Games Third Anniversary Special Edition. Olympic Studies Forum, 2-3 September 2019. Federal University of Sergipe, Aracaju, Brazil

\section{The eSports and Olympic Games: Perspectives of an ongoing debate}

\section{Os e-sports e os Jogos Olímpicos: Perspectivas de um debate em andamento}

\author{
NELSON SCHNEIDER TODT ${ }^{1} \triangle$, ANDRÉ FAGUNDES PASE², ALESSANDRA MARIA SCARTON¹, LUIS

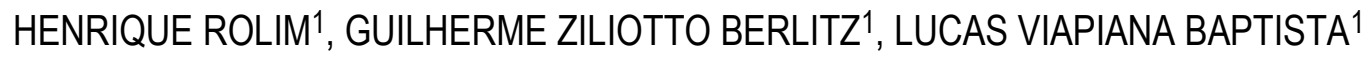 \\ 1Olympic Studies Research Group, Pontifical Catholic University of Rio Grande do Sul, Brazil \\ 2Pontifical Catholic University of Rio Grande do Sul, Brazil
}

\begin{abstract}
This literature review paper aims to understand the different perspectives on the inclusion or not of eSports in the Olympic Games programme. ESports (electronic sports) popularity among world's youth population grows daily. The eSports phenomenon became a new form of entertainment with its own financial means and cultural practices, very close related to streaming technology, and ultimately bringing new questions and challenges for the so-called 'traditional sports' field. The audience success sparked the gaming industry with a considerable economic growth, transforming a backyard practice in the beginning of the century into a worldwide recognized activity; a megaevent in terms of infrastructure and media coverage. Therefore, in a short period of time the debate about eSports become recognized as 'sport' as well as to be include into the Olympic Games programme emerged. In recent years, some decisions heated this debate. For example, at the occasion of the 6th Summit of the International Olympic Committee (IOC), held at Lausanne (Switzerland) in 2017, eSports were placed on the agenda about the future of the Olympic Movement. As a result of the Summit discussions, the IOC concluded that (1) eSports have been demonstrating a sharp growth with the youth of several countries and could become a platform for engagement between this young population and the Olympic Movement; (2) eSports can be considered a physical activity and the players training intensity could be compared to 'traditional sports' athletes; (3) to be recognized as sport by the IOC, the contents of eSports must not violate the Olympic Values; and (4) in order to the IOC grant recognition, an international
\end{abstract}

\footnotetext{
Corresponding author. Olympic Studies Research Group, Pontifical Catholic University of Rio Grande do Sul, Brazil. http://orcid.org/0000-0002-5179-781X

E-mail: nelson.todt@pucrs.br

Supplementary Issue: Rio 2016 Olympic Games Third Anniversary Special Edition. Olympic Studies Forum, 2-3 September 2019. Federal University of Sergipe, Aracaju, Brazil.

JOURNAL OF HUMAN SPORT \& EXERCISE ISSN 1988-5202

(c) Faculty of Education. University of Alicante

doi:10.14198/jhse.2020.15.Proc1.10
}

S94 $|2020|$ Proc1| VOLUME 15

C 2020 University of Alicante 
eSports federation must be created to ensure the compliance of the rules and regulations of the Olympic Movement (IOC, 2017). Moreover, another important milestone was the announcement of the Intel World Open, an eSports event organized by Intel in partnership with the IOC that is going to be held in July 2020 and it will be a pre-event for the Tokyo Olympic Games. In this sense, this paper has an exploratory approach and the Content Analysis was the interpretational method used. The main results indicated three categories of understanding about the eSports and the Olympics relation: (1) the eSports does not have the necessary features to be considered 'sport', then could not be included in Olympic programme; (2) the eSports activity is comparable to 'traditional sports', therefore could be part of the Olympic programme; and (3) the eSports could have its own 'Olympic event', a parallel competition such as Paralympics. In this sense, the relationship between the eSports and the Olympic Movement is undeniable and despite the different arguments analysed in paper, there are other perspectives remaining to be considered. Thus, a second phase of this study is currently under development and it includes the eSports and Olympics protagonists point of view about the research topic. Keywords: eSports; Olympic Games; Electronic Sports; Olympic Movement.

\section{Cite this article as:}

Todt, N.S., Pase, A.F., Scarton, A.M., Rolim, L.H., Berlitz, G.Z., \& Baptista, L.V. (2020). The eSports and Olympic Games: Perspectives of an ongoing debate (in Portuguese). Journal of Human Sport and Exercise, 15(1proc), S94-S110. doi:https://doi.org/10.14198//hse.2020.15.Proc1.10 


\section{INTRODUÇÃO}

Criado nos anos 1980 como atividade de lazer ou entretenimento para crianças e adolescentes, os jogos eletrônicos (vídeo game) tornaram-se na última década uma indústria extremamente lucrativa e com uma audiência global. Esse fenômeno, encapsulado no conceito de e-Sports ${ }^{1}$ (Esportes Eletrônicos), atrai principalmente jovens (16 a 24 anos), do sexo masculino (71\%) e com alto poder aquisitivo (What To Know About Targeting Esports Fans in 2019, 2018). Esses jovens gamers (expressão popular) participam de uma média de até quatro campeonatos/torneios mensais. No Brasil, $27 \%$ dos jovens já assistiram um torneio de e-Sports (What To Know About Targeting Esports Fans in 2019, 2018) e estima-se que há mais de 75 milhões de jogadores no país, gerando um lucro de 1.5 bilhão de dólares para indústria dos games (Esports in Brazil, 2018). Dessa forma, o Brasil hoje possui 7.6 milhões de seguidores declarados de e-Sports, o que significa $5.3 \%$ da população online do país e a terceira maior percentagem mundial (abaixo apenas da China e dos Estados Unidos) (Esports in Brazil, 2018). Além disso, 1.2 milhão de fãs de e-Sports não assistem futebol e desses $43 \%$ tem entre 10 e 20 anos (Esports in Brazil, 2018).

Tamanha popularidade e mercado, fez com que a profissionalização do "esporte" virasse uma realidade. Confederações, ligas, clubes, equipes e atletas fazem parte da estrutura "esportiva" subsidiada por desenvolvedores de jogos, patrocinadores e mídia (online e tradicional). Eventos como o Campeonato Brasileiro de League of Legends (CBLoL), organizado pela Riot Games, possuem uma premiação total de $\mathrm{R} \$ 200$ mil e tiveram quase um milhão de espectadores online por hora; já o campeonato de "Counter Strike" organizado pela ESL One em Belo Horizonte esse ano, distribuiu uma premiação de 200 mil dólares, atingiu a marca de mais de um milhão por hora de espectadores online e teve em torno de 15 mil pessoas assistindo a competição no Ginásio Mineirinho (Esports in Brazil, 2018). "Atletas" brasileiros de "Counter Strike" como Gabriel "FalleN" Toledo (Equipe "Made In Brazil", Brasil) e Epitacio "Taco" Pessoa (Equipe "Team Liquid", Holanda), já receberam mais de 750 mil dólares em premiação no ano de 2018 e possuem juntos mais de um milhão de seguidores na rede social Twitter e mais de meio milhão no Facebook (Esports in Brazil, 2018). "FalleN" inclusive foi considerado a personalidade mais influente do e-Sports brasileiro em 2015 (Uol, 2015). As plataformas de transmissão de vídeo online Twitch e YouTube são as mais usadas para exibir as competições do universo dos e-Sports. Nessas plataformas, os "streamers" (quem transmite) tornaram-se peça fundamental para divulgação e captação de marcas dispostas a investir nos games. No Brasil, "YoDa" é o top "streamer", possuindo 1.1 milhão de seguidores que já assistiram mais 14 milhões de horas do game "League of Legends" no seu canal no Twitch; seguido de "Alanzoka", com um milhão de seguidores e 11.2 milhões de horas assistida do game "Fortnite" (Esports in Brazil, 2018). Tamanha audiência chamou a atenção do maior canal de televisão esportivo a cabo, o SporTV, que desde 2016 adquiriu os direitos de transmissão do CBLoL.

Com tudo isso, é inegável o impacto econômico gerado pela indústria do e-Sports (inclusive na indústria esportiva em geral) apesar do desconhecimento do tema por $47 \%$ da população online (Esports in Brazil, 2018), a falta de clareza gerado pelo termo e-Sports (Olsen, 2015) e da discussão acerca do impacto negativo dos vídeo games nos jovens (Yue, 2018). Contudo, a reprodução do modelo esportivo tradicional, principalmente com relação a organização de um sistema de eventos de grande escala, proporcionou aos investidores uma segurança sobre o futuro dos e-Sports (What To Know About Targeting Esports Fans in 2019, 2018). Assim, ao tornar-se um big player da indústria esportiva, os e-Sports naturalmente começaram a ser pauta de inclusão dos Jogos Olímpicos, o maior produto do Movimento Olímpico. Nesse sentido, em

\footnotetext{
1 Para este trabalho escolhemos a seguinte definição de e-Sports: Um fenômeno emergente de uma abordagem organizada e competitiva para jogos de computador (Seo \& Jung, 2016).
} 
2017, no 60 Summit do Comitê Olímpico Internacional (COI) realizado em Lausanne (Suíça), os e-Sports foram colocados na agenda de reuniões sobre o futuro do Movimento Olímpico. Após as reuniões, o COI concluiu que (1) os e-Sports vem demonstrando um crescimento acentuado junto a juventude de diferentes países e podem torna-se uma plataforma para engajamento desses com o Movimento Olímpico; (2) e-Sports competitivos podem ser considerados uma atividade física e os jogadores envolvidos se preparam e treinam com uma intensidade que pode ser comparada aos atletas de esportes tradicionais; (3) para ser reconhecido como esporte pelo COI, o conteúdo dos e-Sports devem obrigatoriamente não infringir os Valores Olímpicos; e (4) também para ser reconhecido pelo COI, futuramente é necessária uma confederação que garanta 0 cumprimento das regras e regulamentos do Movimento Olímpico (IOC, 2017b). Além disso, o COI se comprometeu a dialogar com os jogadores, desenvolvedores de jogos eletrônicos e a Associação Global de Federação Esportivas Internacionais (sigla em inglês, GAISF). Dessa forma, em julho de 2018, o COI e a GAISF promoveram o "e-Sports Forum" em Lausanne (Suiça) para debater e explorar possíveis sinergias para construir um entendimento e definir uma plataforma para um futuro engajamento entre e-Sports, a indústria dos jogos e o Movimento Olímpico (IOC, 2018).

A inclusão de seis jogos eletrônicos (Arena of Valor, Clash Royale, Hearthstone, League of Legends, Pro Evolution Soccer e StarCraft II) nos Jogos Asiáticos Jacarta-Palembang 2018 (evento regional reconhecido pelo COI) foi um marco histórico para os e-Sports e uma sinalização de que os mesmos estão a caminho dos Jogos Olímpicos. Assim, a notícia de que os Jogos Olímpicos de Paris em 2024 poderiam também colocar sSports como evento de demonstração não surpreendeu os especialistas, porém trouxe à tona a discussão sobre a natureza dos e-Sports.

Nos últimos anos, os Jogos Olímpicos vêm sofrendo um impacto na sua credibilidade, seja na questão do custo para sedia-los ou com relação a temas específicos como o doping. Além disso, a queda de interesse dos millennials em relação aos Jogos Olímpicos (Chang, 2016) é um dos grandes desafios do Comitê Olímpico Internacional que busca rejuvenescer o seu produto incorporando novos esportes (surfe, escalada esportiva, skate, basquete 3×3 farão parte do programa Olímpico em Tóquio 2020) e a criação dos Jogos da Juventude (criado em 2010 e que teve a sua terceira edição em Buenos Aires, nesse ano de 2018). No sentido reverso, os e-Sports tornaram-se uma febre entre os jovens e com um grande potencial comercial e de expansão. Apesar do presidente do COI, Thomas Bach, declarar que não há espaço nos Jogos Olímpicos para e-Sports de caráter violento (Wade, 2018) e do CEO da empresa de apostas online Unikrn, Rahul Sood, enfatizar que uma incorporação dos e-Sports nos Jogos Olímpicos beneficiaria muito mais ao COI do que aos stakeholders dos jogos eletrônicos (Tarrant, 2018), existe uma grande incógnita com relação à inclusão dos games nos Jogos Olímpicos.

É importante ressaltar que, no Sistema Olímpico atual, o COI está longe de ser a única organização que influencia nas decisões acerca do Movimento Olímpico. Os patrocinadores e a mídia possuem voz ativa e precisam ser levados em conta nessa complexa teia de relações (Chappelet, 2015). Assim, Parry (2018) levanta a hipótese da pressão de patrocinadores, como a Alibaba (especializada em comércio online), que fechou uma parceria histórica com o COI em 2017 (IOC, 2017a), pela busca em elevar o status dos e-Sports para esporte através da inclusão nos Jogos Olímpicos e, dessa forma, maximizar suas receitas através do mercado esportivo.

Diante desse cenário, esse estudo visa ampliar a discussão à cerca do tema, contribuindo para o debate sobre a inserção (ou não) dos "games" nos Jogos Olímpicos e o seu reconhecimento enquanto atividade física no âmbito do Movimento Olímpico. Para tanto, o objetivo deste trabalho é compreender as diferentes perspectivas sobre a inclusão ou não dos e-Sports nos Jogos Olímpicos. 


\section{MATERIAL E MÉTODOS}

Esta pesquisa é de caráter exploratório bibliográfico. Devido ao caráter pioneiro do projeto no Movimento Olímpico brasileiro, esse estudo exploratório visa ampliar o conhecimento do tema, a fim de formular problemas mais precisos ou criar hipóteses que possam ser pesquisadas por projetos posteriores.

Para garantir a adequação do tratamento dos dados dentro da abordagem proposta, foi utilizada a técnica de Análise de Conteúdo (Bardin, 2011).

\section{ANÁLISE E DISCUSSÃO DOS DADOS}

A partir da revisão de literatura realizada, identificam-se características que serão analisadas e discutidas a partir de quatro categorias: (1) aspecto social, (2) institucionalização, gestão e administração, (3) aspectos físicos, humanos e de habilidade dos e-Sports e (4) para-sport.

\section{Aspecto Social}

Um dos pilares analisados, quando se trata de esportes eletrônicos, é, sem dúvida alguma, o aspecto social. Como toda prática, seja de jogos eletrônicos ou de esportes tradicionais, o convívio social existe. Contudo, alguns autores mencionam problemas no que tange a prática dos e-Sports, que muitas vezes possui um olhar cético em relação à sua prática exacerbada.

Os jogos eletrônicos, do ponto de vista filosófico e sociológico, aparentam não estar à altura dos esportes. A definição dos games como sendo virtuais, não incorporados, não saudáveis e não humanos alimenta os céticos da modalidade quanto ao seu status (Hemphill, 2005). Nesta linha, 0 autor que reforça que a ligação da parte social e aptidção física não é essencial para o entendimento da natureza dos jogos de computador, mas sua ausência reforça a reputação duvidosa perante ao público em geral. Logo, para Hemphill, há uma demarcação entre a atividade virtual e o esporte, onde os jogos eletrônicos são chamados de jogos e não de esporte. Os games, em um sentido amplo, são interpretados como algo menor do que algo real, e cita o futebol como exemplo, onde se é dito que o futebol é mais do que um jogo, pois há um entendimento de que o mesmo é considerado uma religião, um identidade nacional e uma manifestação coletiva. Já a palavra virtual, no raciocínio do autor, possui conotações de algo real para questões práticas. No entanto, não é substancialmente real. Ademais, Hemphill entende que ser virtual remete à algo artificial, não natural.

Da mesma forma, Jenny, Manning, Keiper e Olrich (2016) entendem que a sociedade em geral vê os vídeo games como a antítese do esporte. Isto é, empiricamente falando, o sedentarismo causado pelo número de horas frente à tela de computador e/ ou vídeo game está correlacionado a diminuição do exercício físico e aumento da obesidade. Logo, estas causas levam ao desencorajamento quando se trata em jogar jogos eletrônicos e assistir à televisão (Hemphill, 2005).

Estes prejuízos geralmente ocorrem com os adolescentes: para Yue (2018), os prejuízos psicológicos que atingem os jovens praticantes de e-Sports está no sentido de que esta modalidade pode trazer uma sensação de vazio, também que podem servir como um refúgio quando se trata de convívio social, ou até mesmo podendo demonstrar aspectos violentos. Levando em consideração a imensa popularidade dos eSports e seus live broadcasters stars entre os adolescentes, outros comportamentos desagradáveis, segundo Yue, podem se manifestar: depressão, vulgaridade e desonestidade, o que, para 0 autor, se mostram como influências negativas aos adolescentes. Em comparação com adultos, jovens são mais 
suscetíveis a aderirem aos fatores negativos, devido à sua curiosidade, e menor autodisciplina, o que pode ampliar efeitos negativos na indústria dos games.

Outro problema mencionado quanto a indústria dos e-Sports é a falta de moralidade em competições da modalidade. Yue (2018) cita problemas quanto ao espírito esportivo e leis esportivas, rendimentos desiguais, comparação irrealista, renda invertida entre narradores e atletas e trapaça para obter cliques, que vem se mostrando uma tendência crescente. A falta de educação social dentro da indústria e supervisão social são os problemas relatados por Yue, que não só afetam o desenvolvimento saudável da indústria, mas também alimentam os adolescentes com exemplos ruins de valores e moral.

Ademais, problemas de saúde também aparecem durante a prática dos e-Sports: ao tratar da questão de saúde, Yue (2018) relata que online games, incluindo e-Sports, têm sido grandes obstáculos para o estilo de vida saudável de adolescentes. $O$ exemplo citado é o do padrão aceitável quanto ao número de horas em frente à tela de computador ou televisão, o chamado daily entertainment screen time. 0 autor relatou um aumento no tempo de entretenimento frente a eletrônicos, fortalecendo a postura não saudável. Para reforçar seu argumento, Yue trouxe dados de uma pesquisa realizada por ele, onde jovens entre 16 e 25 anos passam $33 \%$ do seu tempo de lazer em jogos online e e-Sports. Sendo assim, no entendimento do autor, embora departamentos chineses tenham aderido a medidas de controle, há uma dificuldade no monitoramento dos jovens, o que restringe o acesso dos mesmos a outras atividades. Isso inevitavelmente toma tempo para a participação dos jovens em outras atividades esportivas tradicionais (Yue, 2018).

Em outra direção, alguns autores entendem que os e-Sports podem vir a ser uma ferramenta útil para 0 aspecto social. Yue (2018) entende que a indústria dos jogos eletrônicos pode se tornar a nova energia cinética da indústria dos esportes tradicionais. Isto é, uma inserção dos e-Sports nos Jogos Olímpicos poderia ser um atrativo para os jovens, que poderiam se interessar pelos Jogos Olímpicos, além de ajudar os jovens a entender o significado da atividade física, dos valores dos programas dos esportes tradicionais, levando ao entendimento e à promoção do Espírito e Cultura Olímpica.

Para Llorens (2017), um atributo social importante dos e-Sports é o fair play. Ela reconhece que o ambiente dos eSports, principalmente em âmbito amador, ainda é muito tóxico. Há casos onde os jogadores podem desistir da partida a qualquer momento, sem penalização. Outros casos de trapaça também ocorrem em jogos não profissionais, o que, segundo Llorens, compromete o entendimento de fair play. Sendo assim, no âmbito profissional, atitudes como agressão verbal, comportamento antidesportivo são passíveis de punição, por isso a existência de árbitros, que monitoram os atletas. Em alguns casos mais graves, a maior punição que pode ser aplicada é o banimento (ban) do perfil do usuário.

Por sua vez, Jenny et al. (2017) entendem que os e-Sports tendem a possuir um valor social e também econômico. Isto é, os e-Sports podem vir a ter implicações positivas, quando se trata de um potencial engajamento e associação do fenômeno em eventos como o intercollegiate athletics ou outras manifestações esportivas, como, citando um exemplo dado pelos autores, os Jogos Olímpicos. Os autores citam outro fator que pode ser explorado, caso a modalidade venha a ser reconhecida como esporte: a possibilidade de aumentar o número de jovens americanos que praticam Educação Física. Isso pode ser feito por meio dos chamados Motion-Based Video Gaming (MBVG), que poderia diminuir a distância entre atividades sedentárias e atividades físicas esportivas.

Na percepção de Martončik (2015), as parties (grupo de jogadores em um determinado modo de jogo) nos e-Sports tem como principal objetivo a interação entre os jogadores - isto é, um desejo pelo contato social - 
, uma vez que essas parties, segundo o autor, promovem e geram as condições necessárias para esse encontro. $O$ centro dessas partidas está voltado à cooperação entre jogadores, sua comunicação e também a oportunidade de conhecer novas pessoas. Isso culmina, segundo esta lógica, em uma diminuição na vontade de competir e vencer. $O$ autor ainda afirma que o atrativo principal para os jogadores de e-Sports é a natureza de jogar jogos na função multiplayer, para assim atingir uma interação social maior, seja ela em um ambiente virtual ou real. O conceito de jogo, a priori, é deixado de lado na opinião de Martončik. Um exemplo abordado pelo autor é o caso de países menores, como a República Checa e a Eslováquia, onde esses jogadores de e-Sports normalmente se encontram em ambientes externos aos jogos, estreitando, assim, laços de amizade. Logo, Martončik entende que os e-Sports não se resumem apenas em jogos de computador e 0 ato de jogar por si só, mas também como um meio de satisfação de várias necessidades, como o pertencimento a um grupo ou equipe online.

\section{Institucionalização, gestão e administração}

Características institucionais e de governança são um assunto delicado no campo dos e-Sports. Muitos autores criticam a atuação dos órgãos encarregados, além da desestruturação dos mesmos, se comparados aos esportes tradicionais.

Parry (2018) analisando a situação dos esportes tradicionais, entende que um esporte realmente atingiu 0 nível ideal de institucionalização quando se consegue evidenciar uma representação coerente em âmbito nacional e internacional. Para o autor, o problema dos e-Sports está ao interpretarmos em qual estágio e que tipo de organização estamos procurando para contar como institucionalização. $O$ autor entende que não existem associações compostas por membros ou uma sociedade em comum de donos de clubes supervisionando os e-Sports, que possam criar uma pessoa legal responsável para definir as questões institucionais. $O$ que se vê, de acordo com Parry, é um processo de produção disperso, onde os editores organizam seus próprios torneios para seus jogos. Isto contribui para a constante mudança nos e-Sports, onde os organizadores de torneios desistem rapidamente de jogos que perdem popularidade, sendo prontamente substituído por outro.

Na visão de Yue (2018), existem problemas quanto a profissionalização dos e-Sports. Após investigações preliminares, atletas em clubes chineses se aposentam precocemente (com pouco mais de vinte anos), com um ciclo pequeno de exercícios e uma falta de acompanhamento dos atletas. Além disso, os treinos de profissionais possuem uma alta intensidade, onde ultrapassam as 50 horas semanais, que podem gerar exaustão física e fadiga. Yue considera ainda que o aparecimento destes problemas mostram que há espaço para melhora deste estágio atual da indústria dos e-Sports, onde deve haver um cuidado maior na questão de proteção e gestão dos atletas por parte das instituições. Outra característica frágil da governança, institucionalização e gestão dos e-Sports, na percepção deste autor, está nas políticas administrativas sobre e-Sports no meio da pesquisa acadêmica, que estão praticamente em branco.

Já a questão de gestão administrativa dos e-Sports também foi abordada em Yue (2018), que trouxe como exemplo a realidade chinesa: o problema da indústria, neste caso, está no envolvimento dos diferentes organizações. Existem muitas organizações engajadas na administração da indústria dos games, contudo, esse poder está disperso, espalhado. Ainda nesta linha, afirma que o corpo principal dessas organizações é desconhecido, e a maioria das medidas tomadas são políticas emergenciais, o que não garante uma continuidade e efetividade das mesmas, tornando-as insatisfatórias.

Já na perspectiva de Jonasson e Thiborg (2010), apesar da existência de sistemas organizados dentro do mundo dos e-Sports, os mesmos estão longe de serem organizados como como os esportes competitivos 
modernos. Os autores mencionam um caso ocorrido em seu país de origem, Suécia, onde duas associações (Goodgame e Swedish e-Sport Association), na tentativa de estabelecerem alguns padrões no caráter institucional (como por exemplo a organização dos atletas), não obtiveram sucesso. O problema institucional não se manifesta apenas em âmbito nacional: internacionalmente, Jonasson e Thiborg afirmam que não há uma forte federação unificada que regule as competições e atletas de forma adequada. $O$ que existe, de acordo com os autores, são múltiplas organizações com diferentes propostas e agendas. Ao afirmar que a situação institucional é um solo fértil para evidenciar a instabilidade dentro do campo dos e-Sports, os autores entendem que as organizações não podem ser consideradas autônomas e auto reguladoras, ao contrário do esporte moderno. Isso se dá pelo fato de existir uma certa dependência das organizações dos jogos eletrônicos perante as empresas comerciais.

Estes fatores sugerem a necessidade de reformulação no cenário institucional dos e-Sports: ao fazer uma projeção do cenário dos games em um futuro próximo, Jonasson e Thiborg consideram que os jogos eletrônicos ainda não estão à altura dos padrões formais estabelecidos pelos esportes modernos. Um dos argumentos levantados é a necessidade de reconhecimento dos e-Sports como esporte por parte do COI. Para serem formalmente aceitos, os e-Sports esbarram no conflito institucional, onde os jogos eletrônicos devem possuir uma organização autônoma e independente, que administre a atividade no âmbito internacional. Além disso, devem aderir ao Movimento Olímpico, ao Código de Anti-Doping e seguir as regras do COI, sempre agindo de acordo com a Carta Olímpica do COI (Jonasson \& Thiborg, 2010).

De modo semelhante ao que ocorreu na Suécia, Besombes (2016) traz a situação institucional no território Francês, que apesar das tentativas, os atores dos e-Sports jamais conseguiram provar sua legitimidade perante o Ministério do Esporte. Um exemplo levantado pelo autor foi a tentativa de reconhecimento durante o e-Sport Summit em Novembro de 2015.

Ademais, diversas associações organizadoras de eventos citadas pelo autor que ambicionavam a legitimidade da prática "e-sportiva" competitiva a nível federal acabaram por se enfraquecerem ou se extinguirem (Mora, 2005 como citado em Besombes, 2016, p. 12).

Atualmente, existem associações responsáveis por organização de eventos capazes de fidelizar e estruturar uma comunidade de jogos eletrônicos, como por exemplo a Masters Français du Jeu Vidéo. Entretanto, segundo Besombes (2016), a institucionalização em âmbito federal resta pendente, pois ainda não é visualizada como legítima por parte dos ministérios franceses da Juventude e do Esporte. Isso se dá pelo fato de uma estruturação dissipada, uma forma de descentralização de associações, tornando esse modelo um pouco confuso aos olhos dos competidores e do público, além de não atingir um sucesso midiático aceitável. Desta forma, o autor entende que o modelo federal esportivo não parece ser, a priori, apropriado ao campo do esporte eletrônico, por três principais razões: A primeira se baseia na ideia de que os jogos eletrônicos são propriedades intelectuais dos desenvolvedores, que são responsáveis pela criação, desenvolvimento e comercialização destes games.

Besombes (2016) também refere que não existem campeonatos de jogos de estratégia, jogos de tiro ou de combate, mas sim, campeonatos de Starcraft, Street Fighter e Counter Strike. O que não parece ser bem aceito pelo Ministério, é a necessidade de parceria entre as associações e empresas privadas, para que as mesmas possuam o direito de organizar eventos dos jogos promovidos pelas empresas. A segunda razão traz 0 aspecto da independência dos e-Sports frente às instâncias centralizadoras, o que fez com que os jogos eletrônicos fossem organizados e administrados de uma maneira original e inédita, possuindo certa autonomia. Esse sistema isentou os clubes de e-Sports de qualquer obrigação institucional, além de, receber 
0 apoio dos jogadores, que, em um primeiro momento, apelidaram o sistema de clans. Essa ideia de independência fez com que parte da comunidade "e-sportiva" se tornasse cética em relação aos investimentos das instâncias federais no campo do e-Sport profissional, que contestavam sua legitimidade. $O$ terceiro argumento mostra a visão de um possivvel desinteresse das instituições esportivas nacionais, que, segundo Besombes, jamais prestaram atenção no fenômeno e-Sport. Este desinteresse do movimento esportivo se dá pelo fato de haver uma ideia imprecisa quanto à interpretação do termo esporte, além de haver uma oposição de ideias entre atividade física e jogos eletrônicos. $O$ autor acrescenta que 0 caráter infantil, violento e não socializador gerou uma condenação pública dos e-Sports, fato que aparentemente pode ter contribuído para o afastamento das instituições esportivas em relação aos e-Sports.

Desde uma perspectiva mais positiva do caráter institucional, existem, segundo alguns autores, argumentos positivos que mostram a evolução da administração dos e-Sports. De acordo com Llorens (2017), os eSports atingiram um passo internacional importante referente a infraestrutura institucional que regula a prática e a organização de competições da modalidade, onde empresas foram capazes de criar regulamentações a fim de estruturar a prática profissional dos e-Sports. Um exemplo citado é a Riot Games². Segundo a autora, a empresa, ao cuidar do desenvolvimento do jogo League of Legends, elevou a institucionalização do game no mundo dos e-Sports.

Para a autora, a Riot Games conseguiu organizar eventos bem estruturados e competitivos, assim promovendo o professional gaming na sua melhor forma. Isso se dá pelo fato de haver uma boa divisão dos campeonatos em diversos meses do ano, além de uma série de políticas exclusivas da empresa que devem ser respeitadas pelos times, como por exemplo, a impossibilidade de jogar outras competições que não sejam da Riot Games e da Electronic Sport Leagues (ESL). Isso auxilia na organização e estruturação do jogo League of Legends, que para a autora ilustra o sucesso da institucionalização desta prática como qualquer prática esportiva competitiva seguida por milhões de pessoas. Além disso, a World Esports Association (WESA), outro órgão institucional internacional, possui parceria com a ESL, o que faz com que exista uma exclusividade quando os clubes assinam um contrato, exigindo que os mesmos participem somente de competições da ESL (Llorens, 2017).

Jonasson e Thiborg (2010) afirmam a existência de um órgão institucional no fenômeno dos e-Sports, que pode ser comparado com associações nacionais dentro do esporte tradicional moderno. Essa associação se encontra na Coreia do Sul, (Korea e-Sport Association), que fornece serviços e apoio a seus membros. Dentre as atividades, estão a organização de competições, onde a associação se responsabiliza por alojar os atletas e também a entregar um estádio com infraestrutura suficiente para competições e treinamentos. O autor continua afirmando que essa associação também organiza seminários, simpósios e exposições, além de apoiar o cenário de criação de regras e normas, assim como realizam o registro de pro gamers e auxiliam na formação de equipes nacionais.

Nesta mesma direção, Seo e Jung (2016), defendem que já há um processo crescente de institucionalização dos e-Sports. Eles acreditam que esse processo vai gradualmente construir um desenvolvimento cultural do ato de jogar e-Sports, direcionando-os a uma profissionalização e institucionalização cada vez mais consistentes. Um exemplo é a International Esports Federation (leSF), com sede na Coreia do Sul, cujo objetivo principal é criar padrões internacionais no mundo dos e-Sports, integrando o desenvolvimento de cada país ao instituir um padrão internacional (leSF, 2013). Essas organizações atuam em diferentes

2 Riot Games é uma empresa americana fundada como um estúdio de jogos independente em 2006 por Brandon "Ryze" Beck e Marc "Tryndamere" Merril, em Los Angeles. (https://pt.wikipedia.org/wiki/Riot_Games). 
funções, como por exemplo, supervisionando e desenvolvendo regras da prática dos e-Sports, atingindo uma estrutura coerente e organizada para o consumo dos e-Sports (Seo \& Jung, 2016).

\section{Aspectos físicos, humanos e de habilidade}

Para Parry (2018), os aspectos físico, humano e de habilidade são característicos nos esportes tradicionais. Assim, ao trazer estes aspectos para o contexto dos e-Sports, o autor considera que todos esportes tradicionais requerem um desenvolvimento e exercício da habilidade física humana. Esse fator elimina algumas atividades cujo exercício não necessita significativamente de algum tipo de aprendizado de habilidade. Nesta linha, Parry entende que um mero exercício de rotina, como caminhar, não necessita de um componente de habilidade específico, por isso, não pode ser considerado esporte. Já nos e-Sports, os jogos eletrônicos falham em empregar um decisivo controle completo do corpo e das habilidades corporais, e assim, não contribuem para o desenvolvimento humano e habilidades que, segundo 0 autor, são necessárias no Esporte Olímpico. Praticar embaixadinhas, ou até mesmo melhorar a habilidade ao manusear um teclado não contribuem para o desenvolvimento humano completo da mesma maneira que 0 Esporte Olímpico contribui (Parry, 2018).

Já o aspecto físico é considerado quando o movimento produz o resultado, como por exemplo, no tiro esportivo. Ao contrário disso está o xadrez, por exemplo, que não se caracteriza como esporte pelo fato de que o movimento é irrelevante para o resultado do jogo, e também pelo fato de o movimento de mover a peça poder ser realizado por qualquer outra pessoa que não seja o jogador (Parry, 2018; Jenny et al., 2017). Jenny et. al. ainda mencioanam que, da mesma forma ocorre nos e-Sports, onde a maneira na qual o botão de um controle é pressionado não influencia diretamente no resultado em uma competição de e-Sports.

Por outro lado, Parry não nega a existência de ação física e esforço nos e-Sports, contudo, o autor questiona se a parte física envolvida é adequada. Enquanto Parry cita que nos esportes tradicionais o domínio de execução e o domínio de aplicação coincidem (isto é, quando o atleta efetua o tiro é exatamente o mesmo momento no qual ele mira buscando o alvo), nos e-Sports as habilidades executadas são obrigatoriamente transpostas para um domínio virtual. Sendo assim, o autor entende que esse argumento desqualifica o status dos e-Sports como esportes, pois há uma escassez de fisicalidade direta nos jogos eletrônicos.

Jenny et al. ainda consideram os e-Sports como sendo possuidores de coordenação motora fina, apenas. Logo, esse contraste entre realidade física e realidade virtual não pode passar despercebido. Os autores ilustram este argumento com o exemplo de um ginasta, onde o mesmo, para executar suas habilidades, exibe movimentos chamados de controle preciso e completo do corpo. Além disso, o ginasta deve encarar uma situação do mundo real, onde há o risco de lesões durante cada habilidade treinada. Por outro lado, 0 gamer se utiliza apenas de movimentos motores finos das mãos, controlando um avatar (personagem) cujas lesões e possível morte são virtuais, logo, não há dor. Isto é, não existem consequências reais, o jogador apenas recomeça seu jogo (Jenny et al., 2017). Os autores acreditam que, enquanto os e-Sports não adotarem os motion-based vídeo games (MBVGs) onde os movimentos motores amplos estão incluídos dentro do jogo, o público em geral pode não aceitar os e-Sports como sendo um esporte real.

Por sua vez, no que tange o aspecto humano, Parry relata que o esporte tradicional é uma empresa humana, isto é, o comando está sempre ao alcance dos humanos. Sendo assim, Parry cita a Fórmula 1 e o motor boating como sendo motor sports e não esportes Olímpicos, pelo fato do elemento "motor" estar contribuindo significativamente e diretamente para o resultado final. Já a Vela, é considerado Esporte Olímpico pois permanece majoritariamente nas mãos de humanos (Parry, 2018). Parry cita ainda o exemplo de robot wars, 
onde as interações, em um nível humano, são inadequadas, assim como os e-Sports, onde os competidores também estão fisicamente distanciados da ação.

Logo, para um jogo ser considerado esporte, a habilidade/movimento físico deve estar presente, e o êxito na sua execução deve possuir um impacto direto na execução da tarefa (Parry, 2018; Jenny et al., 2017).

Na perspectiva do aspecto físico, Yue (2018) entende que os e-Sports, até um certo ponto, possuem traços de alta intensidade. Contudo, relata que nem todos os games podem ser considerados e-Sports, sendo este universo restrito àqueles que possuem uma alta intensidade de operação, tornando-se esportes maduros. Seguindo neste raciocínio, o autor afirma que os jogadores de e-Sports dependem altamente de seus corpos, por necessitarem de uma velocidade de reação apurado e um alto número de ações por minuto (APM), por exemplo.

A demanda física e psicológica nas competições de e-Sports é elevada, e, nesse sentido, e-Sports auxiliam na melhora da coordenação viso-manual e no desenvolvimento da inteligência (YUE, 2018).

Ainda neste entendimento físico, Yue (2018) ressalta que os atletas de e-Sports necessitam de uma grande quantidade de treinos e preparações pré partidas, desta forma, não sendo dependentes apenas de seu talento, mas também de um grande número de horas de prática. Além disso, adiciona que os clubes profissionais estão cada vez mais dando ênfase aos treinos diários e aos técnicos e auxiliares técnicos, sendo esses fatores, para o autor, preparações essenciais que não cessarão em se desenvolver. Para Yue, os e-Sports ainda não possuem grande variedade quando se trata do volume das atividades físicas, porém, ressalta que, com o avanço tecnológico, a interação humano-computador será inevitável, consequentemente podendo gerar um grande progresso físico. $O$ autor ressalta que muitos games possuem uma intensidade $\mathrm{e}$ gasto de energia equiparáveis, ou até mesmo superiores a de alguns esportes tradicionais. Um bom exemplo são alguns jogos de lutas, desenvolvidos com novos dispositivos utilizáveis, os wearable devices ${ }^{3}$. Yue também entende que os atributos físicos dos humanos como sendo o sujeito determinam as diferenças subjetivas na cognição. Isto é, tanto amadores quanto profissionais treinam e jogam em dispositivos semelhantes, onde a grande diferença é exatamente o nível de competição devido aos fatores mencionados anteriormente, que 0 autor chama de características incorporadas.

No aspecto humano, Yue (2018) diz que a proposta dos e-Sports é de buscar confronto com outras pessoas, assim atingindo um nível de satisfação pessoal. Para isso, afirma que estes equipamentos eletrônicos são apenas ferramentas utilizadas para atingir esse tipo de confronto. $O$ autor entende os e-Sports como um fenômeno cultural, criado pela recombinação da Tecnologia da Informação e ações humanas. Sendo assim, entende-se que o desenvolvimento dos e-Sports tem como principal aspecto a criação humana. Assim como a bola de basquete é uma ferramenta para o esporte basquete, Yue (2018) considera que o "líderes" por trás dos jogos dos e-Sports são as próprias pessoas. Ressalta, ainda, que ao contrário de muitos jogos eletrônicos, os e-Sports representam uma existência especial que está a parte de muitos jogos eletrônicos (Yue, 2018).

Hemphill (2005), por sua vez, utiliza o argumento dos filósofos (que entendem a fisicalidade como essencial para diferenciar esportes dos games) para afirmar que existem argumentos convincentes de que alguns tipos de games de computadores podem ser considerados esporte (como exemplo as simulações de

3 O termo, em tradução livre, é algo como aparelhos vestiveis, que simboliza uma nova abordagem da computação para qualquer tecnologia baseada em dispositivos que estejam conectados diretamente ao usuário. 
esportes). 0 autor prossegue e relata que é necessário demonstrar como a habilidade envolvida nos jogos eletrônicos pode ser entendida como sendo suficientemente física, a ponto de qualificarmos como esporte. Em outras palavras, o autor afirma, na mesma visão de Yue (2018), que esses tipos de games não são virtuais ou simplesmente imaginários, mas sim práticas esportivas de habilidade e concretas.

No aspecto humano, Hemphill (2005) entende que a realidade virtual é um estímulo do computador no qual cada um é imerso e interativo com objetos virtuais e pessoas. Para o autor, imersão é a extensão que esquece a máquina humana ou incorpora a máquina como sendo uma experiência de um corpo com vida. Para o autor, essa imersão é facilitada por meio do uso de materiais como o joystick, controles etc. Hemphill cita ainda os jogos de computadores cuja interatividade envolve movimentos esportivos convencionais, como 0 golfe, onde o estilo de batida na bolinha é diferente e influencia diretamente na posição da bola real que aparece na tela. De acordo com o autor, habilidades motoras convencionais como por exemplo o golf swing tem consequências no trajeto gerado pelo computador. Da mesma forma, mudanças de peso no esqui está correlacionado com os movimentos de esqui em uma corrida eletrônica. Em outras palavras, o autor entende que sim, destreza manual ou corporal possui relevância nas ações eletrônicas.

Ademais, Hemphill entende que o uso de habilidade motora fina ou ampla (se similar aos movimentos esportivos convencionais ou não) que controla personagens gerados por computadores ou objetos podem ser considerados suficientemente físicos para qualificar jogos de computador como esporte em seu direito. O exemplo citado pelo autor relata uma história onde seu filho efetua uma roubada (speecie) de bola em um jogo de Futebol Australiano. Para Hemphill, esse fato é importante por 2 motivos: $1^{0}$ : apesar de ser um jogo em terceira pessoa, o jogador entendeu que ele mesmo realizou a ação ao dizer que havia roubado a bola no jogo pela primeira vez. Disso, Hemphill extrai que a distintição entre o game player e o personagem do jogo desaparecem, logo, o jogador se torna parte do jogo; o segundo ponto apresentado pelo autor está relacionado com a habilidade e a interatividade efetiva. A aquisição das habilidades necessárias do controle do jogo não são tarefas simples, e tomam um certo tempo a serem dominadas. Hemphill finaliza dizendo que, assim como qualquer outro esporte, existe certo movimento corporal, incluindo várias habilidades motoras, que devem se tornar de alguma forma automáticas, a fim de executar a tática e estratégia por parte do atleta. Ressalta, ainda, que seria possível considerar habilidade ou destreza a forma de inteligência esportiva. Como sendo uma habilidade esportiva, a destreza poderia ser considerada como conhecimento estratégico e tático.

Da mesma forma, Jenny et al. (2017), entendem, que superficialmente, os e-Sports possuem traços de skills. A maneira com que se manipula controles e os personagens, por parte dos jogadores, requer um certo nível de coordenação.

Nesta mesma linha de pensamento, Llorens (2017) acrescenta que os e-Sports requerem um alto nível de habilidade para dominar os comandos do jogo, precisão e concentração, controle do corpo, resistência, movimentos rápidos e estratégia de equipe. Isso acaba por excluir alguns jogos, como o World of Warcraft, cujo objetivo é o profile upgrading e não fundamentalmente uma interação competitiva. Sendo assim, as habilidades são consideradas cruciais dentro do esporte, visto que há a necessidade de dominar as ferramentas do jogo, sempre respeitando regras e o fair play.

A autora destaca ainda que o caráter físico também é primordial para a importância dos e-Sports, e que a atividade física é muito semelhante à do tiro (um esporte olímpico). Ainda no quesito fisicalidade, Llorens (2017) ratifica a relevância deste fator, ao dizer que, se a questão física não fosse relevante, então as lesões dos gamers não iriam prejudicar, dificultar a performance dos mesmos: os jogadores podem sofrer sérias 
lesões no pulso e no cotovelo, causados durante os treinamentos, que podem resultar em aposentadoria precoce.

Por sua vez, o fator humano é evidenciado quando Llorens exemplifica uma situação onde a palavra eletrônico é entendida como um meio pelo qual o esporte é jogado. Isto é, assim como a água é um meio para o polo aquático ou para o surf, o meio dos e-Sports é a tecnologia, ou melhor, o eletrônico. A autora reforça esse raciocínio ao afirmar que não devemos analisar a ação dos personagens no jogo, mas sim analisar as habilidades dos gamers e sua contribuição para a performance dos personagens. Reforça, também, que os e-Sports devem ser tratados como qualquer meio específico que um esporte tradicional possa ter.

Para Besombes (2016), o senso comum tende opor os e-Sports das atividades físicas e esportivas. Contudo, ele entende que há uma certa destreza digital do jogador, que incorpora o corpo à prática dos jogos eletrônicos. $\mathrm{O}$ jogador coloca em prática toda a complexidade das dimensões biológicas, psicológicas e sociais enquanto joga, engajando todo seu corpo na prática dos jogos de vídeo games (Roustan, 2003 como citado em Besombes, 2016, p. 5). Sendo assim, Besombes afirma que o jogador não percebe mais como executa as ações e como controla seus dedos, mas sim incorpora o personagem virtual dentro dele mesmo. Para exemplificar, Besombes traz um exemplo de um jogador que faz seu personagem correr utilizando 0 controle: quando ele executa a ação, o gamer não pensa em apertar os botões somente, ele apenas corre. Ademais, a partir de um certo nível de experiência, geralmente ligado a aprendizagem por repetição, o nível de consciência reflexiva diminui. Logo, o jogador esquece das ações manuais para direcionar sua atenção ao personagem virtual que o jogador encarna.

O uso das mãos, reforça Besombes, mostra a necessidade que as mesmas possuem para representar digitalmente a interação entre os personagens (seja em um confronto, um deslocamento do avatar, etc.). 0 jogador deve interpretar a informação advinda do jogo virtual para assim traduzir esse entendimento para ações reais no teclado e no mouse. Isso depende majoritariamente da agilidade seja nos movimentos, na tomada de decisão e na execução.

Logo, afirma Besombes (2016), que para sucesso de tais tarefas, as capacidades motoras reais do jogador sob o teclado vão determinar em grande escala o andamento dos comportamentos virtuais executados pelo personagem. Uma combinação de toques equivocada, um gesto técnico equivocado, e a partida pode ser considerada perdida. Sendo assim, existe então, para Besombes, uma relação direta entra a ação do jogo e a motricidade.

Estudos mostram que ao participar em jogos de e-Sports, existe uma rotina de treinamento a fim de desenvolver uma habilidade específica necessária nos jogos competitivos. 0 treino no meio dos e-Sports serve para otimizar as habilidades dos jogadores ao máximo, para que os mesmos alcancem uma alta performance dentro do ambiente dos e-Sports (Wagner, 2007 como citado por Seo \& Jung, 2016, p. 636). Dentro desse entendimento, há uma grande necessidade de treinar outros aspectos, como trabalho em equipe e principalmente o controle completo do corpo e compostura (Witkowski, 2012 como citado por Seo \& Jung, 2016, p. 636). Esses argumentos destacam a seriedade do jogo competitivo, devido aos diversos tipos de habilidades e competências, que também diferenciam 0 ato de jogar no campo dos e-Sports com outras formas de jogo virtual (Seo \& Jung, 2016).

Ainda, nos e-Sports existe uma tendência ao identificarmos os tipos específicos de equipamentos utilizados pelos jogadores, uma vez que os teclados e mouses são criados com objetivo específico: os modos de jogos 
competitivos. Por isso, entende-se que a atuação e os movimentos necessários são de alta intensidade e demandam aparelhos que potencializam a performance dos jogadores (Slocum, Thompson \& Chaparro, 2005 como citado por Seo \& Jung, 2016, p. 645).

\section{Para-sport}

Besombes (2016) entende que os esportes eletrônicos deveriam ser reconhecidos e adotados por um modelo de estruturação mais espetacular e mediatizado que o modelo associativo francês, porém em uma competição paralela.

Besombes sugere um novo modelo de organização, onde as Federações Esportivas delegam a realização de eventos para empresas privadas ou permitem com que os desenvolvedores dos jogos organizem eles mesmos seus campeonatos e eventos associados.

Este modelo organizacional se alia ao conceito de para-esporte, definido como uma prática física competitiva, regulamentada por um código de jogo relevante de uma instância superior autônoma, desconectada das organizações esportivas reconhecidas como legítimas (Bordes, 2015 como citado por Besombes, 2016, p. 14).

Temos como exemplo os grandes eventos de e-Sports organizados por empresas como a Major League Gaming e a Evolution Championship Series (que atuam majoritariamente na América do Norte), Electronic Sports League e Dreamhack (Europa) e também a Electronic Sports World Cup (com alcance em todo 0 mundo). Esses torneios são financiados por investidores privados, onde os mesmos decidem as modalidades de jogo, a regulamentação, arbitragem, sanções, recompensas e pré-requisitos. Esse modelo se diferencia do modelo das associações esportivas, pois, os jogadores são escolhidos pelos investidores para atuarem em torneios competitivos, com um viés explicitamente comercial, o que faz com que a competição possua uma notória diferença entre o amadorismo e profissionalismo (Besombes, 2016).

Para Besombes (2016), o jogo League of Legends (LOL) poderia ser o game ideal para se encaixar à ideia que 0 autor chamou de para-sport, ou modelo paralelo do esporte, tendo em vista sua estruturação de seu sistema competitivo e regulamentário instituído pela Riot Games. Isso pelo fato da criação de uma nova variação do LOL, que aproxima um pouco mais o dispositivo organizacional dos e-Sports ao do esporte moderno. $O$ chamado Challenger Series visou criar uma continuidade entre amadores e profissionais, tendo em vista seu modelo de meritocracia de ascensão por divisões. Isso mostra aos jogadores o caminho que deve ser percorrido para que os mesmos atinjam o nível profissional, e se assemelha ao esporte moderno pelo fato de existirem divisões bem definidas (municipal, regional, nacional, internacional, etc.), onde os uma equipe pode ascender até o topo, que seriam os campeonatos profissionais. Para reforçar seu argumento, 0 autor compara a popularidade de um evento dos e-Sports com um evento de esportes tradicionais. Em outubro de 2015, em uma Arena de Berlim (Alemanha), aproximadamente 17.000 pessoas foram acompanhar o duelo entre duas equipes sul-coreanas de e-Sports, com uma audiência de 36 milhões via internet, em um evento da Riot Games. A final decisiva da NBA (National Basketball Association), reuniu 20.000 espectadores in loco e mais de 23 milhões via televisão. Com uma audiência extraordinária, essa comparação, entende Besombes, de certa forma, poderia assegurar uma progressão dos eventos de eSports, onde o prêmio das equipes vencedoras, financiados pela Riot Games, poderiam chegar a 1 milhão de euros.

Jonasson e Thiborg (2010) sugerem um novo evento pré Jogos Olímpicos, proposta que representa outro indício de que ambos podem caminhar lado a lado. A Intel, em parceria com o Comitê Olímpico Internacional, 
realizará o Intel World Open, evento competitivo de e-Sports que acontecerá entre 22 e 24 de julho de 2020, funcionando como pré-evento dos Jogos Olímpicos. Street Fighter V (2016) e Rocket League (2015) foram as modalidades escolhidas, sendo que cada uma dará uma premiação de US\$250 mil ao primeiro lugar. Essa será a primeira vez que e-Sports integram uma Olimpiada, mostrando que, competições de e-Sports paralelas, separadas dos Jogos Olímpicos, é um caminho possível.

Vale ressaltar que as modalidades escolhidas cumprem as condições estabelecidas pelo COI (respeito aos valores olímpicos e ausência de violência nos jogos). Rocket League é uma espécie de futebol com carros e Street Fighter $V$ é um jogo de luta não letal. São jogos relativamente fáceis de serem assistidos e entendidos pelo público geral e Street Fighter $V$ é um jogo de uma franquia aclamada no Japão, que faz parte da cultura do país, fazendo com que sua escolha também se encaixe bem dentro do ambiente multicultural e de união entre os povos do movimento olímpico.

\section{CONCLUSÕES}

A partir dos resultados apresentados a partir das categorias: (1) aspecto social, (2) institucionalização, gestão e administração, (3) aspectos físicos, humanos e de habilidade dos e-Sports (4) para-sport, pode-se identificar claramente três vertentes, conforme apresentado a seguir:

A primeira, representada por autores como Besombes (2016), Hemphill (2005) Jenny et al. (2017), Jonasson e Thiborg (2010), Parry (2018) e Yue (2018) considera que os e-Sports não possuem todas as características necessárias para serem considerados esportes.

Uma segunda vertente, defendida por Besombes (2016), Hemphill (2005), Jenny et al. (2017), Llorens (2017), Martončik (2015), Seo e Jung (2016), Jonasson e Thiborg (2010), Yue (2018), entende que a prática dos e-Sports é análoga à prática dos esportes tradicionais.

Identifica-se também uma terceira vertente, defendida nos textos de Besombes (2016) e de Jonasson e Thiborg (2010), que reconhece as colocações das duas anteriores e levanta a possibilidade dos e-Sports como uma categoria de competição paralela aos Jogos Olímpicos.

Finalmente, pode-se dizer que os e-Sports e o Movimento Olímpico mostram indícios de aproximação. Um exemplo disso, como já destacado no anteriormente, é o campeonato Intel World Open, um pré evento dos Jogos Olímpicos de Tóquio 2020, que ocorrerá entre 22 e 24 de julho. Esse pode vir a ser um passo importante para um futuro engajamento dos games junto ao Movimento Olímpico.

Uma segunda fase deste estudo está atualmente em desenvolvimento e inclui o ponto de vista dos protagonistas dos esportes eletrônicos e das Olimpíadas sobre o tema da pesquisa.

\section{REFERÊNCIAS}

Bardin, L. (2011). Análise de conteúdo. [São Paulo]: Ediç̧oes 70.

Besombes, N. (2016). Les jeux vidéo compétitifs au prisme des jeux sportifs: du sport au sport électronique. Sciences du jeu, (5), 1-19. https://doi.org/10.4000/sdj.612

Chappelet, J. (2015). From Olympic administration to Olympic governance. Sport In Society, 19(6), 739751. https://doi.org/10.1080/17430437.2015.1108648 
Chang, C. (2019). How the Olympics Lost Millennials. Retrieved 26 November 2018, from https://newrepublic.com/article/136096/olympics-lost-millennials

Hemphill, D. (2005). Cybersport. Journal of the Philosophy of Sport, 32(2), 195-207. https://doi.org/10.1080/00948705.2005.9714682

Intel World Open. (2019). Intel News Fact Sheet. Retrieved from https://newsroom.intel.com/wpcontent/uploads/sites/11/2019/09/intel-world-open-fact-sheet.pdf

IOC and GAISF to host Esports Forum - Olympic News. (2019a). Retrieved 24 June 2019, from https://www.olympic.org/news/ioc-and-gaisf-to-host-esports-forum

IOC and Alibaba Group launch historic long-term partnership as Alibaba becomes Worldwide Olympic Partner through 2028. (2019b). Retrieved 24 June 2019, from https://www. olympic.org/news/ioc-andalibaba-group-launch-historic-long-term-partnership-as-alibaba-becomes-worldwide-olympicpartner-through-2028

IOC. Communique of the Olympic Summit. (2019c). Retrieved 24 June 2019, from https://www.olympic.org/news/communique-of-the-olympic-summit

Jenny, S., Manning, R., Keiper, M., \& Olrich, T. (2016). Virtual(ly) Athletes: Where eSports Fit Within the Definition of "Sport". Quest, 69(1), 1-18. https://doi.org/10.1080/00336297.2016.1144517

Jonasson, K., \& Thiborg, J. (2010). Electronic sport and its impact on future sport. Sport in society, 13(2), 287-299. https://doi.org/10.1080/17430430903522996

Llorens, M. (2017). eSport gaming: the rise of a new sports practice. Sport, Ethics and Philosophy, 11(4), 464-476. https://doi.org/10.1080/17511321.2017.1318947

Martončik, M. (2015). e-Sports: Playing just for fun or playing to satisfy life goals? Computers in Human Behavior, 48, 208-211. https://doi.org/10.1016/j.chb.2015.01.056

Esports in Brazil: Key Facts, Figures, and Faces | Newzoo \& Esports BAR | Newzoo. (2019). Retrieved 17 February 2019, from https://newzoo.com/insights/trend-reports/esports-in-brazil-key-factsfigures-and-faces

Olsen, A. (2015). The Evolution of Esports: An analysis of its origin and a look at its prospective future growth as enhanced by Information Technology Management tools (Master Degree). Coventry University.

Parry, J. (2019). E-sports are Not Sports. Sport, Ethics and Philosophy, 13(1), 3-18. https://doi.org/10.1080/17511321.2018.1489419

Seo, Y., \& Jung, S. U. (2016). Beyond solitary play in computer games: The social practices of eSports. Journal of Consumer Culture, 16(3), 635-655. https://doi.org/10.1177/1469540514553711

Tarrant, J. (2018). Not everyone in favour of Esports in Olympic fold. Retrieved 26 November 2018, from https://www.reuters.com/article/us-esports-olympics-idUSKCN1MLOB9

Uol. (2019). As dez maiores personalidades do e-sport brasileiro em 2015. Retrieved 26 November 2018, from http://mycnb.uol.com.br/noticias/3513-as-dez-maiores-personalidades-do-e-sport-brasileiroem-2015

Wade, S. (2019). Bach: No Olympic future for esports until 'violence' removed. Retrieved 26 November 2018, from https://apnews.com/3615bd17ebb8478ab534691080a9a32a

What To Know About Targeting Esports Fans in 2019 - GlobalWeblndex. (2019). Retrieved 20 March 2018, from https://www.globalwebindex.com/reports/esports-trends

Yue, Y. (2019). Research on eSports and eSports industry in China. China sport science, 38(4), 8-21. Retrieved 26 May 2019, from https://library.olympic.org/Default/doc/SYRACUSE/174917/researchon-esports-and-esports-industry-in-china-yang-yue? Ig=en-GB 


\section{(c) $(7)(\mathrm{E})$}

This work is licensed under a Attribution-NonCommercial-NoDerivatives 4.0 International (CC BY-NC-ND 4.0). 